\title{
STUDENTS' READINESS FOR STEM LEARNING WITHIN THE CONTEXT OF NATIONAL EDUCATION REFORM
}

\author{
Rita Birzina, Tamara Pigozne, Dagnija Cedere \\ University of Latvia, Latvia
}

\begin{abstract}
STEM (science, technology, engineering, and mathematics) education nowadays becomes more and more topical; however, students' performance in these subjects is rather low and only a small part of them decide to study these sciences therefore it is important to rouse students' interest in these subjects already at school. It is important to acquire not only the knowledge of the subject but also the transversal skills, thus, the organization of the teaching/learning process becomes more significant. Schools of Latvia start implementing the teaching/learning content and approach that correspond to the new standards of basic and general secondary education, which incorporates four innovative aspects in the science domain: the promotion of the content acquisition through teachers' reciprocal collaboration; the use of ICT (Information Communication Technologies) as a platform for engineering technological solutions; learning through doing and engagement in discussions and other activities for making socially responsible decisions. The aim of the study is to find out students' readiness to learn STEM in the context of innovative approaches of the national education reform. To reach the aim, the research question was set - to what extent and in which way are students ready to learn STEM? Using the QuestionPro e-platform, 257 students of Latvian general comprehensive schools were surveyed and the meta-analysis of factors of thematically respective selected questions was performed. The obtained empirical results were compared with the four aspects of the innovative approach pertaining to the education reform in the science domain. The study resulted in isolating main four factors: the course of the teaching/learning process, the feedback, the use of ICT and technologies little used in the acquisition STEM. The found factors comprised all the innovations of the science domain put forward by the national education reform, which means that students already at the pre-reform stage are ready to acquire STEM subjects in an innovative way.
\end{abstract}

Keywords: innovation, national education reform, readiness, secondary school students, STEM learning. 


\section{Introduction}

STEM education during the last decade has become the topic of international discussions (Kennedy \& Odell, 2014). The appeal to improve STEM education continues also at the beginning of the twenty-first century (Ritz \& Fan, 2015) and this, to a certain extent, is also connected with the impact of this century on the environment and society causing the urgency of improving STEM education in the world (Kelley \& Knowles, 2016).

There are different reasons why STEM education attracts the attention. Many countries are involved in discussions and are experimenting with STEM education in different levels of education and with the focus on different subjects. There are countries that hope to find ways how to improve students' understanding about the content of STEM subjects so that they are able to acquire better this knowledge, other countries, in turn, place emphasis on teacher education with the intention of improving the teaching/learning methods of STEM to create a greater interest in students and to make students' acquisition of the knowledge easier. Other countries hope to increase students' performance in tests so that the country could rise above other countries in the international student assessment because students' low performance in STEM subjects is a problem. Yet, for other countries it is important to increase the number of students studying STEM in higher education institutions to ensure the future STEM workforce (Ritz \& Fan, 2015). The changing global economics and the needs of the workforce describe this situation, which indicates that the world lacks well-qualified STEM experts and teachers (Kennedy \& Odell, 2014 ) to meet the $21^{\text {st }}$ century challenges where people are not only smart but also skilful.

Researchers of science education emphasise increasingly the importance of integrative, interdisciplinary STEM (science, technologies, engineering science and mathematics) education to urge students to get to know the natural world applying inquiry and problem solving experience (Asghar et al., 2012). This means that the importance of STEM education can be analysed from several aspects - from the point of view of the teaching/ learning process and learning outcomes in the nearest and further perspective. Qualitative education of science, technology, engineering science and mathematics is important for students to gain success in future. Integrated STEM education is one of the ways how to make learning more attractive and appropriate for students (Stohlmann et al., 2012).

One of the issues in the context of the national education reform in Latvia to be faced during its implementation is students' readiness for learning STEM. As the readiness to learn correlates with learning outcomes, students' goal of learning is affected by the change in knowledge, 
understanding, skills, habits, values and attitudes gaining new personal experience (Kearney \& Garfield, 2019; Tiven et al., 2018; DiBenedetto \& Myers, 2016). This means that it is important to acquire not only the subject knowledge but also transversal skills therefore the organization of the teaching/learning process at school becomes more significant. Schools of Latvia start implementing the teaching/learning content and approach that correspond to the new standards of basic and general secondary education, for students to gain knowledge, skills and attitudes necessary for life nowadays (Skola 2030, 2019).

At present, the implementation of STEM in Latvia employs two approaches - the old and the new. According to the old approach the schools with the humanitarian direction in Latvia teach the integrated science course but in general comprehensive schools each STEM subject is taught separately. There can be a situation in schools specializing in teaching science and mathematics that one or two STEM subjects are taught in-depth. According to the new Skola 2030 reform schools will choose the directions of teaching/learning domains and the chosen subjects will be taught in-depth. The new standard for general upper secondary education will offer three levels of curriculum (general level, basic level and advanced level). Approximately $70 \%$ of the time spent studying the curriculum will be spent on the compulsory content, while approximately $30 \%$ of the curriculum will be offered according to a future career path/educational pathway of the student (National Reforms..., 2020). The reform in the education of Latvia is substantiated by the fact that today's children must learn to live in the continuously changing world and in future they must be ready to create the economic, political, social and culture environment not experienced before. Students in the present stage of education do well the tasks that require remembering or acting in standard situations, however, they lack skills to delve into and process diverse data, to work in a team, to offer solutions to non-standard situations, to form connections between the theoretically acquired and the experienced in their life, to analyse what has been done and to set aims for further work (Skola 2030, 2019).

The national education reform is implemented to introduce innovations in the science domain in four aspects: (1) the promotion of the content acquisition through teachers' mutual collaboration in teaching interdisciplinary themes; (2) the use of ICT as a platform for problem solving, emphasizing the engineer technical thinking; (3) learning through doing, performing practical activities, exploring, experimenting, modelling and searching for regularities; (4) engagement in discussions and other activities for making socially responsible decisions (Andersone, 2020).

The present study adapted and supplemented the above mentioned aspects (Figure 1). 


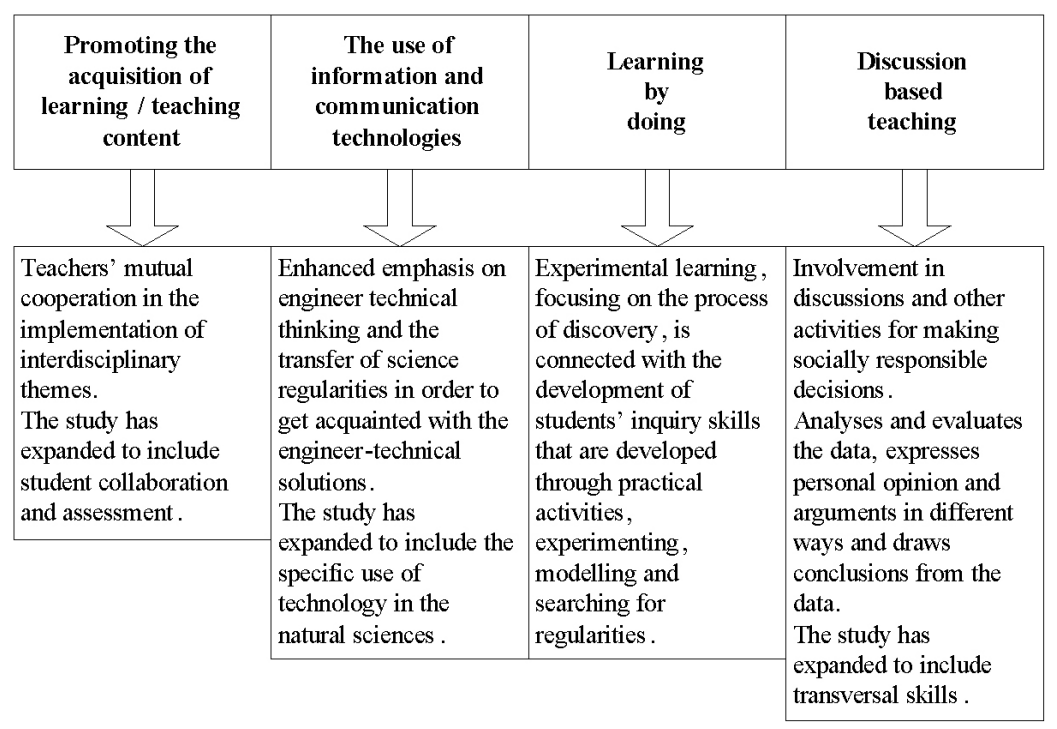

Figure 1. The use of innovative aspects in the study (adapted from Andersone, 2020; Skola 2030, 2019)

Based on the innovative aspects of the national education reform, the aim of the study was defined - to find out students' readiness to learn STEM in the context of the national reform and the research question was set - to what extent and in which way students are ready to learn STEM.

\section{Method}

The study is performed adapting the context of innovative aspects of the national education reform. Using the QuestionPro e-platform, students of Latvia's general comprehensive schools were surveyed. The selection of schools was carried out in accordance with the regions of the territory of Latvia - Riga, Vidzeme, Kurzeme, Latgale and Zemgale, sending out questionnaires to the heads of methodological associations of schools in these regions. The obtained empirical results were compared with the four aspects of the innovative approach of the education reform, performing the meta-analysis of factors of thematically respective selected questions from the secondary school students' survey carried out in 2018.

Data are obtained using open and closed questions on 5-point Likert scale in the online platform QuestionPro. The data analysis uses descriptive statistics $(M, S D)$, exploratory factor analysis and the analysis of correlations, defining the linear Pearson's correlation ratio among the factors. The analysis of discrete questions, based on the non-parametric data, used the non-linear Spearmen's correlation ratio. 
The participants of the study were 257 students of whom $63 \%$ are female and $37 \%$ are male respondents (Figure 2). The majority of respondents (84\%) are students from gymnasia, representing schools from Riga, Vidzeme, Kurzeme, Latgale and Zemgale regions.

\begin{tabular}{|c|c|c|c|c|c|c|c|}
\hline $\begin{array}{c}\text { Grade } \\
\text { of learning }\end{array}$ & & \multicolumn{2}{|c|}{$\begin{array}{c}10^{\text {th }} \\
(\mathrm{n}=97)\end{array}$} & \multicolumn{2}{|c|}{$\begin{array}{c}11^{\text {th }} \\
(\mathrm{n}=112)\end{array}$} & \multicolumn{2}{|c|}{$\begin{array}{c}12^{\text {th }} \\
(\mathrm{n}=48)\end{array}$} \\
\hline Gender & & & $\begin{array}{l}\text { Female } \\
(\mathrm{n}=161)\end{array}$ & & & $\begin{array}{c}\text { Male } \\
(\mathrm{n}=96)\end{array}$ & \\
\hline $\begin{array}{c}\text { Direction } \\
\text { School level }\end{array}$ & & $\begin{array}{c}\text { No direction } \\
(\mathrm{n}=2)\end{array}$ & $\begin{array}{c}\text { Humanitarian } \\
(\mathrm{n}=19)\end{array}$ & $\begin{array}{l}\text { Science } \\
(\mathrm{n}=96)\end{array}$ & $\begin{array}{c}\text { Secondary school } \\
(\mathrm{n}=37)\end{array}$ & $\begin{array}{c}\text { Gymnasium } \\
(\mathrm{n}=215)\end{array}$ & $\begin{array}{l}\text { Other } \\
(\mathrm{n}=21)\end{array}$ \\
\hline
\end{tabular}

Figure 2. Students' profile

Based on the innovative aspects (Andersone, 2020; National reforms..., 2020; Skola 2030, 2019), the system of criteria and indicators was designed (Figure 3).

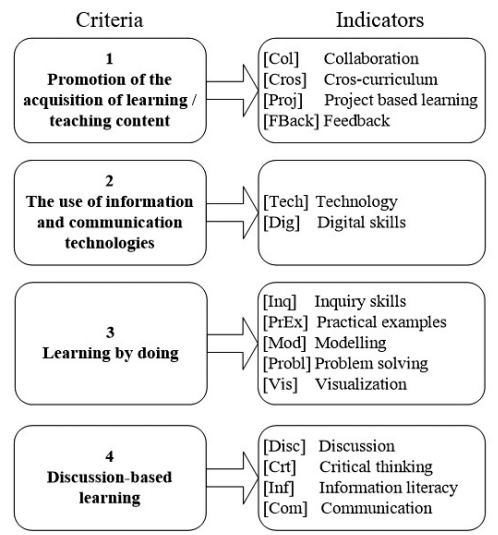

Figure 3. The system of criteria and indicators (adapted from Andersone, 2020; National reforms..., 2020; Skola 2030, 2019)

The developed system of criteria and indicators was used for describing the factors, incorporating the teaching/learning methods and transversal skills used in STEM education.

\section{Results}

The indicator of the sample correspondence KMO was 0.85 and the Bartlett spherical test was significant $(\mathrm{c} 2(257)=2250.94, p<.001)$, confirming the suitability of data for performing the factor analysis. The principal component analysis was carried out using the extraction method of varimax rotation with Kaiser normalization. The analysis used questions the factor load of which was at least 0.45 . To determine the number of 
principal components, the parallel analysis was used which allowed defining the four most important factors that explains $45 \%$ of the dispersion (Figure 4).

\section{Factors describing students' readiness to learn}

The four main factors that describe students' readiness to learn STEM according to the priority aspects of the national education reform were determined in the factor analysis (Figure 4).

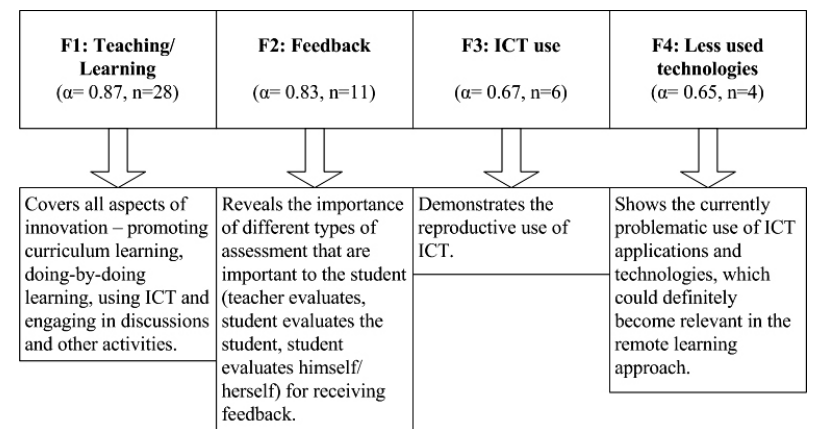

Figure 4. Main factors that are essential for students' STEM learning

\section{Description of factors defined in the study}

Table 1. Descriptive Statistics, codes and factor loading of the F1

\begin{tabular}{|l|l|c|c|c|c|}
\hline Variable & Code & $\boldsymbol{M}$ & SD & Mdn & Load \\
\hline $\begin{array}{l}\text { 3.5. Use of practical } \\
\text { examples }\end{array}$ & {$[\mathrm{PrEx}]$} & 3.89 & .79 & 4 & .68 \\
\hline 3.10. Use of experiments & {$[\mathrm{Inq}]$} & 3.54 & .95 & 4 & .65 \\
\hline $\begin{array}{l}\text { 3.6. Visualization tools } \\
\text { [Vis] }\end{array}$ & 3.73 & .85 & 4 & .61 \\
\hline $\begin{array}{l}\text { 3.16. Development of } \\
\text { inquiry skills }\end{array}$ & {$[$ [Inq] } & 3.75 & .87 & 4 & .61 \\
\hline 3.9. STEM integration & [Crt], [Cros] & 3.40 & .87 & 4 & .61 \\
\hline 3.14. Diverse media & [Tech], [Dig] & 3.32 & .90 & 3 & .60 \\
\hline $\begin{array}{l}\text { 4.13. Problem solving } \\
\text { [Crt], [Probl], } \\
\text { [Com] }\end{array}$ & 3.38 & .96 & 4 & .53 \\
\hline 4.12. Active participation & [Col], [FBack] & 3.46 & .88 & 4 & .53 \\
\hline $\begin{array}{l}\text { 3.13. Use of non-standard } \\
\text { situations }\end{array}$ & [Crt] & 3.26 & .89 & 3 & .52 \\
\hline $\begin{array}{l}\text { 3.11. Assessment of STEM } \\
\text { understanding }\end{array}$ & [FBack] & 3.40 & .88 & 4 & .52 \\
\hline 4.10. Use of argumentation & [Crt], [Disc] & 3.40 & .88 & 4 & .45 \\
\hline
\end{tabular}


The first factor (F1) "Teaching/Learning" ( $\alpha=0.87$, the number of included questions $n=11$ ) (Table 1) cover all four innovation aspects included in the national education reform - promotion of the acquisition of the teaching/learning content [Col], [Probl], [Cros] learning by doing [PrEx], [Inq], [Vis], ICT use [Tech], [Dig] and engagement in discussions [Disc] and other activities. Also the transversal skills suggested by Skola 2030 fall within this factor: critical thinking [Crt] and communication [Com] needed for the problem solving, for giving arguments for the personal opinion, for using non-standard situations and the discussion about the application of science concepts. Differing from the innovations included in the national education reform, secondary students consider feedback [Fback] also important, receiving it from active collaboration $(M=3.46 ; S D=.88 ; M d n=4)$, as well as receiving assessment for the acquisition and understanding the science concepts $(M=3.40 ; S D=.88$; $M d n=4)$. It is interesting that the choice of a high $(M d n=4)$ most frequent answer on the 5 point Likert scale dominates in students' responses, besides, their opinion is rather similar ( $S D=.79-.96)$ and the mean value $(M)$ in all answers is higher than " 3 ".

Table 2. Descriptive Statistics, codes and factor loading of the F2

\begin{tabular}{|l|l|c|c|c|c|}
\hline Variable & Code & $\boldsymbol{M}$ & SD & Mdn & Load \\
\hline $\begin{array}{l}\text { 6.14. Assessment of } \\
\text { classmates }\end{array}$ & [FBack], [Com] & 2.79 & 1.04 & 3 & .82 \\
\hline $\begin{array}{l}\text { 6.15. A classmate assesses me } \\
\text { [FBack], [Com] }\end{array}$ & 2.72 & 1.06 & 3 & .81 \\
\hline $\begin{array}{l}\text { 6.11. The teacher assesses } \\
\text { STEM understanding }\end{array}$ & [FBack], [Com] & 3.28 & .90 & 3 & .53 \\
\hline $\begin{array}{l}\text { 6.13. Student assesses him/ } \\
\text { herself }\end{array}$ & [FBack] & 3.28 & .90 & 3 & .49 \\
\hline $\begin{array}{l}\text { 4.8. Collaboration in projects } \\
\text { [Col], [Proj], } \\
\text { [Com] }\end{array}$ & 3.55 & .83 & 4 & .41 \\
\hline
\end{tabular}

The second factor (F2) "Feedback" ( $\alpha=0.83, n=5)$ (Table 2) presents students' understanding of the importance of different types of assessment. Students confirm that it is important for them to receive the feedback [FBack] both from the classmates and also to assess the classmates him/ herself. Their opinions are slightly different $(S D=1.04-1.06)$, the evidence of that is the mean values of answers $(M=2.72-2.79)$. There is a more similar opinion $(S D=.90)$ in questions about the teacher's assessment (6.11) and self-assessment (6.13). Students, to a certain extent, connect the receiving of the feedback with their mutual collaboration [Col] in projects [Proj] and the communication process [Com]. Students' answers here are more similar $(M=3.55 ; S D=.83 ; M d n=4)$. 
Table 3. Descriptive Statistics, codes and factor loading of the F3

\begin{tabular}{|l|l|c|c|c|c|}
\hline Variable & Code & $\boldsymbol{M}$ & $\boldsymbol{S D}$ & $\boldsymbol{M d n}$ & Load \\
\hline $\begin{array}{l}\text { 5.1. Internet for searching } \\
\text { information }\end{array}$ & $\begin{array}{l}\text { [Inf], [Crt], } \\
\text { [Dig] }\end{array}$ & 4.12 & .92 & 4 & .70 \\
\hline $\begin{array}{l}\text { 2.1. Connection of STEM with } \\
\text { other subjects }\end{array}$ & [Cros] & 4.12 & .92 & 4 & .65 \\
\hline 5.22. Use of Video, DB & $\begin{array}{l}\text { [Inf], [Crt], } \\
\text { [Dig] }\end{array}$ & 3.67 & 1.05 & 4 & .57 \\
\hline 4.6. E-communication & $\begin{array}{l}\text { [Disc], [Crt], } \\
\text { [Com], [Dig] }\end{array}$ & 3.55 & .83 & 4 & .50 \\
\hline 4.15. ICT skills & [Dig], [Com] & 3.55 & .83 & 4 & .48 \\
\hline
\end{tabular}

The third factor (F3) "ICT use" ( $\alpha=0.67, n=5$ ) (Table 3) shows reproductive use of ICT; it is proved by students' opinion on using Internet for searching for information to be used in learning and other study materials (video, animations, data basis et.), where they need such transversal skills as information literacy [Inf], digital skills [Dig] and critical thinking [Crt]. Students' opinions are more similar in the question about searching for the information $(M=4.12 ; S D=.92 ; M d n=4)$, they are less similar in the question about the use of video, data bases and other more specific study materials $(M=3.65 ; S D=1.05 ; M d n=4)$. The Internet is also used for communication [Com] and discussion [Disc]. Respondents equally highly $(M=3.55 ; S D=.83 ; M d n=4)$ assess their ICT skills [Dig]. Students relate the use of ICT not only to separate science subjects (biology, chemistry and physics) but also to the integration of real-life examples [Cros] in other school subjects, thus gaining a more unified idea about all school subjects in general $(M=4.12 ; S D=.92 ; M d n=4)$.

Table 4. Descriptive Statistics, codes and factor loading of the F4

\begin{tabular}{|l|l|c|c|c|c|}
\hline Variable & Code & $\boldsymbol{M}$ & $\boldsymbol{S D}$ & $\boldsymbol{M} \boldsymbol{d n}$ & Load \\
\hline 5.12. Participation in MOOCs & {$[\mathrm{Dig}],[\mathrm{Com}]$} & 1.73 & .93 & 1 & .74 \\
\hline 5.6. Use of e-folio & {$[\mathrm{Dig}],[\mathrm{Com}]$} & 2.02 & 1.06 & 2 & .67 \\
\hline $\begin{array}{l}\text { 5.3. Virtual laboratory works } \\
\text { and simulations }\end{array}$ & {$[\mathrm{Tech}],[\mathrm{Dig}]$} & 2.62 & 1.16 & 2 & .64 \\
\hline 5.13. Visualization e-tools & [Vis], [Dig] & 3.11 & 1.11 & 3 & .53 \\
\hline
\end{tabular}

The fourth factor (F4) "Less used technologies" ( $\alpha=0.65, n=4)$ (Table 4) testifies about a problematic use of STEM applications. Students have the least idea about the open mass-scale online courses $(M=1.73$; $S D=.93 ; M d n=1)$. They also do not use the e-folio $(M=2.02$; $S D=1.06 ; M d n=2$ ) in their learning and very rarely they use virtual 
laboratory works and simulations $(M=2.62 ; S D=1.16 ; M d n=2)$. It is interesting that the use of such technologies and the necessity of digital skills have become very topical in the context of remote learning. It must be noted that exactly virtual laboratory works and simulations during the COVID-19 pandemic became almost the first necessity in the science acquisition. Despite the fact that students assess differently $(M=3.11$; $S D=1.11 ; M d n=3$ ) the use of visual means (5.13. To understand natural phenomena, I learn using different (including electronic) visual aids (models, drawings, graphs and charts, etc.)), probably, they are not always widely employed in all schools.

\section{Mutual correlation of factors and questions}

A Pearson's correlation was run to determine the relationship between factors. It was established that an average good relation exists between F1: Teaching / Learning and F2: Feedback $(r(257)=.50, p<.001)$ and F2 and F3: ICT use $(r(257)=.49, p<.001)$, but there is poor positive correlation between F3 and F4: Less used technologies $(r(257)=.30, p<.001)$.

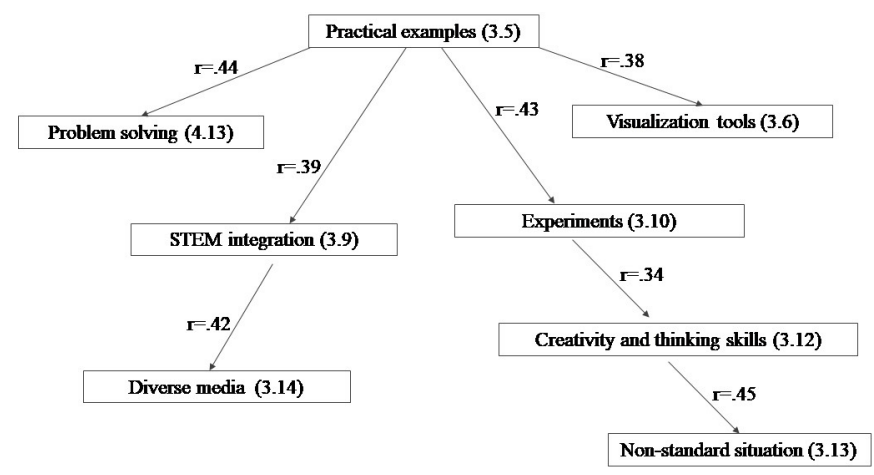

Note: level of significance $p<.001$.

Figure 5. Mutual correlations between questions included in factors

The Spearman's correlation ration was used to determine the mutual relations between the questions included in the factors. As seen in Figure 5, it is important to use Practical Examples (3.5) in the science acquisition that correlates medium closely with 4.13. Problem solving $(r(257)=.44$, $p<.001)$ and 3.10. Experiments $(r(257)=.44, p<.001)$, but there is a weaker positive correlation with 3.9. STEM integration $(r(257)=.39$, $p<.001)$ and 3.6. Visualization $(r(257)=.38, p<.001)$. There is a medium good correlation between STEM integration (3.9) and 3.14. Diverse media $(r(257)=.42, p<.001)$ which confirms that in the acquisition of STEM it is important to use different kinds of information to form a holistic 
understanding about the connection of STEM with the content of other school subjects and the real-life examples. The understanding of this information requires the application of such transversal skills as communication, information literacy and critical thinking. This is also proved by the fact that Creativity and thinking skills (3.12) medium well $(r(257)=.45$, $p<.001)$ correlates with 3.13. Non-standard situation.

\section{Discussion}

Students' readiness to learn is defined by their purposeful action, acquiring the STEM subjects that is connected with the acquisition of knowledge and skills, the change of attitude as well as the choice of methods and strategies offered by the teacher. This is confirmed by factors defined in the study in which the identified innovation aspects are covered in general, at the same time showing a close interaction between separate features of the teaching/learning process and emphasizing those features that are topical in schools today (Figure 6).

Important innovative aspects mentioned in the national education reform have banded together in the first factor that describes the teaching/ learning process in the acquisition of STEM, using practical real-life examples and experiments for developing the inquiry skills, applying diverse media and visualization tools to be able to solve actively the problems, to acquire better the science concepts, combining in an integrative way the science subjects and mathematics for creative activity in non-standard situations.

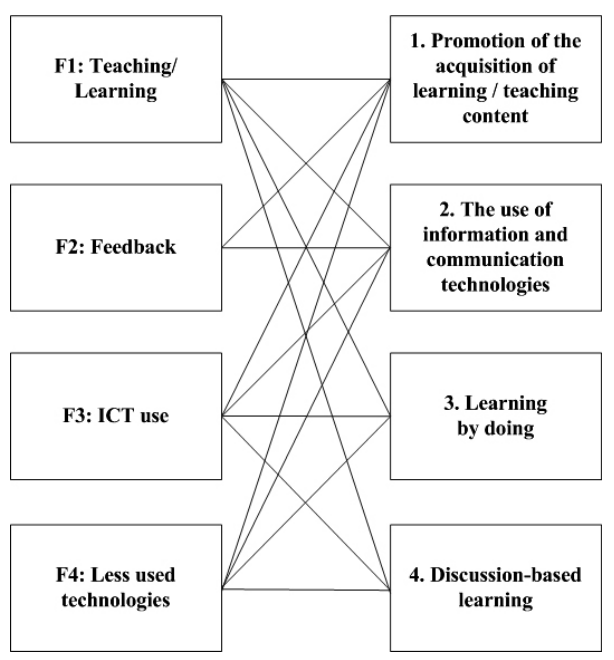

Figure 6. Relation of factors to innovative aspects 
The essential thing is that students emphasize integrated learning because it is based on the constructivism approach and offers students learning by doing in a diverse teaching/learning environment (Thibaut et al., 2018). Such features of the teaching/learning process as receiving the feedback (F2), the use of ICT (F3) and less used technologies (F4) are actualized. Unlike other factors interlinked with all the innovative aspects mentioned in the national education reform, F2: Feedback is only related to two aspects: the promotion of the acquisition of teaching/learning content and the use of ICT. It is possible that the lack of feedback in the aspects of learning by doing and discussion-based learning could be related to the selection of questions, limited by the variable load. The results gained show that receiving and providing feedback in the learning process is an important issue, and this part of the research needs to be further developed. This is also confirmed by the statements of the National Reforms in School Education (2020) that it is important to move from assessment that focused only on recording the outcome to assessment to support student learning. It means that it is advisable to pay more attention to feedback so that the student can improve performance, learn how to act, learn more and demonstrate better results as they learn.

For the time being, both in Latvia and elsewhere in the world there dominates the orientation to separate disciplines and the implementation of integrated contextual learning is a serious challenge the overcoming of which requires the support on all levels because one, first, needs to gain respective knowledge about the pedagogical content (El-Deghaidy \& Mansour, 2015), that will allow realizing the key idea of learning when operating with transdisciplinary concepts (Chesnutt et al., 2019). However, STEM education basically has transformed into a meta-discipline (Kennedy \& Odell, 2014) and an interdisciplinary approach (English, 2016) that focus on solving contextual problems in science, technology, engineering sciences and mathematics (Wang et al., 2011). Research has displayed the difficulties faced by teachers when forming the respective links among the STEM domains, which frequently leads to the situations that students are not interested in science and mathematics when these subjects are taught separately, without linking them with cross-cutting ideas and the real world applications (Kelley \& Knowles, 2016).

Responding to challenges of developing $21^{\text {st }}$ century skills needed for students, one of the innovations offered by researchers is STEM-Based contextual learning (Thibaut et al., 2018), which as a teaching/learning system relies on the philosophy that gives students possibilities to connect the new information with prior knowledge and experience, because it is based on the cognitive situation that comprises constructing of such thinking processes as critical thinking, creative thinking and problem solving (Burrows \& 
Slater, 2015; Harris \& de Bruin, 2018; Thibaut et al., 2018), thus, making learning more meaningful, motivating and preparing students for solving complex problems in new situations (Cook \& Bush, 2018) as well as for creating new knowledge in the future.

Although it can be predictable that STEM competences will be more required in our constantly changing world, it is hard to anticipate which of the many approaches for advancing STEM education will be the most effective. One of the examples how to implement STEM - based activities is the link between modelling and engineering design processes (English, 2017), which is also included in the national education reform as the innovative aspect. STEM educators should ensure possibilities for students to think applying technologies as the driving force of changes, giving arguments how it affects positively and negatively the culture, society, politics, economics and environment (Kelley \& Knowles, 2016).

The data of the present study, which stress the organization of the teaching/learning process that incorporates such characteristic study methods and strategies as experimental and practical learning, inquiry learning, exploration, asking questions and seeking answers, argumentation of the personal opinion, integration of technologies, discussion and mutual collaboration in problem solving and interdisciplinary projects that are characteristic to the acquisition of STEM, comply fully with the above mentioned ideas. It is important to mention the realization of problem-based and project-based learning, which are one of the most effective learning methods (Wilder, 2015), develop engineer technological thinking (Ritz \& Fan, 2015) and describe student's action with apprenticeship, collaboration, accessibility, and independence (Tsinajinie et al., 2021). They are targeted both at acquiring the science content applying practical real-life examples, and improving students' information literacy, critical thinking, decision making, civic responsibility and collaboration skills (Birzina et al., 2021). The development of exploratory cognition is equally important because inquiry makes students think and act as true scientists asking questions, setting hypotheses and performing research (Kelley \& Knowles, 2016). STEM learning is considered to be one of the most influential approaches that favours students to become self-regulated learners, because students in STEM lessons are given many possibilities to develop their thinking skills: metacognitive skills, critical and creative thinking (Anwari et al., 2015). This idea is observed in the study describing the existing connection with using creativity in solving a non-standard situation.

In the context of learning STEM the following is also important: communication, social interaction engaging in partner (one-to-one), small-group (one-to-small group), and whole-class (one-to-many) settings and meaningful activities (Lee et al., 2018). 
Thus, students' readiness for the context of the national education reform is featured by their readiness to learn (1) using real problems, solving social, economic and environmental problems in the context and making decisions; (2) acting experimentally, improving their inquiry skills; (3) interdisciplinary - integrating biology, chemistry, physics and mathematics in problem-based and project-based learning; (4) being creative to explore non-standard situations; (5) collaborate, discuss and communicate, improving their transversal skills; (6) evaluating critically oneself and the others; (7) improving their digital and technological skills. The obtained results agree with the results gained in the previous research (Birzina et al., 2021; Birzina \& Pigozne, 2020; Cedere et al., 2020; Jurgena et al., 2018).

\section{Conclusions}

The study found out to what extent and in which way students are ready to learn STEM subjects. As the study was performed before starting the national education reform, then it is rather safe to maintain that secondary school students (mainly, students of gymnasia) have a relatively good readiness for introducing the innovations and the study actualizes the ways of STEM acquisition.

1. Regarding the promotion of the acquisition of the teaching/learning content, it is important and necessary to have the cooperation between students and teachers for ensuring the interdisciplinary link which can be implemented through transdisciplinary projects, which, in turn, provide the integration of science subjects. This means that in order to work together as a productive team, teachers' assistance is needed and it is possible if all teachers collaborate. According to students, an essential way of mutual collaboration is receiving the feedback both from the classmate and the teacher, thus promoting a meaningful acquisition of the teaching/learning content.

2. As regards the application of information and communication technologies, the use of technologies does not appear in the development of engineer technical thinking. The study does not actualize this particular issue but certainly it can be maintained that there appears a direction for the science acquisition to improve, probably in connecting modelling with the engineering design processes improving the technology literacy. The ICT topicality appears in the all factors defined in the study, even concentrating in two separate factors as "The ICT use" and "Less used technologies". Thus, this aspect is important both from the point of view of the way of using and the development of such transversal skills as digital literacy, information literacy, critical thinking, collaboration and communication. Actually, ICT is more used reproductively - for 
searching for the study information in different internet resources but not for creating productive information. It is interesting that the less used technologies (MOOCs (Massive Open Online Courses), e-folio, virtual laboratory works and simulations) are especially important in the context of remote learning.

3. Learning by doing as it is characteristic in the acquisition of science is the most covered aspect in the study. There is a substantial emphasis on using practical real-life examples, inquiry and experimental teaching/learning methods, modelling and visualization, and the integrative approach in the STEM acquisition. The use of diverse learning methods and strategies in the acquisition of STEM forms a holistic understanding about the relation of STEM with the content of other school subjects and real-life examples. Communication, information literacy and critical thinking skills are needed for the student to develop meaningful awareness of learning and to be able to reach the application of the highest level knowledge in non-standard situations. All in all, methods and strategies mentioned in this factor describe a typical approach of STEM constructive learning.

4. The aspect "Discussion-based teaching" is the most connected with the transversal skills: the use of information literacy, digital skills, critical thinking, problem solving and communication skills in the discussion-based teaching/learning process. The results of the study show that transversal skills are topical in all factors defined in the study that confirm the students' readiness for the acquisition of STEM, expressing their personal opinion, proving it by providing arguments, engaging in discussions, analysing and assessing the data, drawing evidence-based conclusions, making responsible decisions and voicing their civic attitude.

\section{References}

Andersone, R. (2020). Innovations in the improved curriculum content of the competence approach: A case study in Latvia. In V. Dislere (Ed.), The Proceedings of the International Scientific Conference Rural Environment. Education. Personality (REEP) (pp. 213-218). Latvia University of Life Sciences and Technologies. https://doi.org/ 10.22616/REEP.2020.025

Anwari, I., Yamada, S., Unno, M., Saito, T., Suwarma, I., Mutakinati, L., \& Kumano, Y. (2015). Implementation of authentic learning and assessment through STEM education approach to improve students' metacognitive skills. K-12 STEM Education, 1(3), 123-136.

Asghar, A., Ellington, R., Rice, E., Johnson, F., \& Prime, G. M. (2012). Supporting STEM education in secondary science contexts. Interdisciplinary Journal of Problem-Based Learning, 6(2). https://doi.org/10.7771/1541-5015.1349

Birzina R., \& Pigozne T. (2020). Technology as a tool in STEM teaching and learning. In V. Dislere (Ed.), The Proceedings of the International Scientific Conference Rural 
Environment. Education. Personality (REEP), (pp. 219-227). Latvia University of Life Sciences and Technologies. https://doi.org/10.22616/REEP.2020.026

Birzina, R., Pigozne, T., \& Lapina, S. (2021). Trends in STEM teaching and learning within the context of national education reform. In V. Dislere (Ed.), The Proceedings of the International Scientific Conference Rural Environment. Education. Personality (REEP) (pp. 41-49). Latvia University of Life Sciences and Technologies. https://doi.org/ 10.22616/REEP.2021.14.004

Burrows, A., \& Slater, T. (2015). A proposed integrated STEM framework for contemporary teacher preparation. Teacher Education and Practice, 28(2/3), 318-330.

Cedere, D., Birzina, R., Pigozne, T., \& Vasilevskaya, E. (2020). Perceptions of today's young generation about meaningful learning of STEM. Problems of Education in the 21 Century, 78(6), 920-932. https://doi.org/10.33225/pec/20.78.920

Chesnutt, K., Jones, M. G., Corin, E. N., Hite, R., Childers, G., Perez, M. P., \& Ennes, M. (2019). Crosscutting concepts and achievement: Is a sense of size and scale related to achievement in science and mathematics? Journal of Research in Science Teaching, 56(3), 302-321. https://doi.org/10.1002/tea.21511

Cook, K. L., \& Bush, S. B. (2018). Design thinking in integrated STEAM learning: Surveying the landscape and exploring exemplars in elementary grades. School Science and Mathematics, 118(3-4), 93-103. https://doi.org/10.1111/ssm.12268

DiBenedetto, C. A., \& Myers, B. E. (2016). A conceptual model for the study of student readiness in the $21^{\text {st }}$ Century. NACTA Journal, 60(1a), 28-35.

El-Deghaidy, H., \& Mansour, N. (2015). Science Teachers' Perceptions of STEM Education: Possibilities and Challenges. International Journal of Learning and Teaching, 1(1), 51-54.

English, L. D. (2016). STEM education K-12: Perspectives on integration. International Journal of STEM Education, 3(1), 1-8.

English, L. D. (2017). Advancing elementary and middle school STEM education. International Journal of Science and Mathematics Education, 15(1), 5-24.

Harris, A., \& de Bruin, L. R. (2018). Secondary school creativity, teacher practice and STEAM education: An international study. Journal of Educational Change, 19(2), 153179. https://doi.org/10.1007/s10833-017-9311-2

Jurgena, I., Cedere, D., \& Keviša, I. (2018). The prospects of transdisciplinary approach to promote learners' cognitive interest in natural science for sustainable development. Journal of Teacher Education for Sustainability, vol. 20(1), 5-19. https://doi.org/10.2478/ jtes-2018-0001

Kearney, W. S., \& Garfield, T. (2019). Student readiness to learn and teacher effectiveness: Two key factors in middle grades mathematics achievement. RMLE Online, 42(5), 1-12. https://doi.org/10.1080/19404476.2019.1607138

Kelley, T. R., \& Knowles, J. G. (2016). A conceptual framework for integrated STEM education. International Journal of STEM Education, 3(11). Advanced online publication. https://doi.org/10.1186/s40594-016-0046-z

Kennedy, T. J., \& Odell, M. R. L. (2014). Engaging students in STEM education. Science Education International, 25(3), 246-258.

Lee, O., Grapin, S., \& Haas, A. (2018). How the NGSS science instructional shifts and language instructional shifts support each other for English learners: Talk in the science 
classroom. In: Language, Literacy, and Learning in the STEM Disciplines: How Language Counts for English Learners, 35-52.

National Reforms in School Education. (2020). Retrieved from: https://eacea.ec.europa. eu/national-policies/eurydice/content/national-reforms-school-education-34_en

Ritz, J. M., \& Fan, S. C. (2015). STEM and technology education: International state-ofthe-art. International Journal of Technology and Design Education, 25, 429-451. https:// doi.org/10.1007/s10798-014-9290-z

Skola 2030. (2019). Pārmainuu iemesli. Pamatojums. [School2030. Reasons for change. Justification]. Retrieved from: https://skola2030.lv/lv/macibu-saturs/macibu-saturapilnveide/nepieciesamibas-pamatojums (In Latvian).

Stohlmann, M., Moore, T. J., \& Roehrig, G. H. (2012). Considerations for teaching integrated STEM education. Journal of Pre-College Engineering Education Research (J-PEER), 2(1), 28-34. https://doi.org/10.5703/1288284314653

Thibaut, L., Ceuppens, S., De Loof, H., De Meester, J., Goovaerts, L., Struyf, A., Boeve-de Pauw, J., Dehaene, W., Deprez, J., De Cock, M., Hellinckx, L., Knipprath, H., Langie, G., Struyven, K., Van de Velde, D., Van Petegem, P., \& Depaepe, F. (2018). Integrated STEM Education: A Systematic Review of Instructional Practices in Secondary Education. European Journal of STEM Education, 3(1), 1-12. https://doi.org/10.20897/ ejsteme/85525

Tiven, M. B., Fuchs, E. R., Bazari, A., \& MacQuarrie, A. (2018). Evaluating global digital education: Student outcomes framework. Bloomberg Philanthropies and the Organisation for Economic Co-operation and Development.

Tsinajinie, G., Kirboyun, S., \& Hong, S. (2021). An outdoor project based learning program: Strategic support and the roles of students with visual impairments interested in STEM. Journal of Science Education and Technology, 30(1), 74-86. https://doi.org/ 10.1007/s10956-020-09874-0

Wang, H. H., Moore, T., J., Roehrig, G. H., \& Park, M. S. (2011). STEM integration: Teacher perceptions and practice. Journal of Pre-College Engineering Education Research, 1(2), 1-13. https://doi.org/10.5703/1288284314636

Wilder, S. (2015). Impact of problem-based learning on academic achievement in high school a systematic review. Educational Review, 67(4), 414-435. https://doi.org/10.1080/ 00131911.2014.974511 